\title{
ANÁLISE FLORÍSTICA E FITOSSOCIOLÓGICA DO COMPONENTE ARBÓREO DA FLORESTA OMBRÓFILA MISTA PRESENTE NA RESERVA FLORESTAL EMBRAPA/EPAGRI, CAÇADOR, SC - BRASIL
}

\author{
Hugo Alberto Rivera Herrera ${ }^{1}$, Nelson Carlos $\operatorname{Rosot}^{2}$, Maria Augusta Doetzer Rosot ${ }^{3}$, \\ Yeda Maria Malheiros de Oliveira ${ }^{3}$
}

${ }^{1}$ Eng. Florestal, M.Sc., Corporação Nacional Florestal do Chile (CONAF), Santiago, Chile - hugo.rivera@ conaf.cl

${ }^{2}$ Eng. Florestal, Dr., Depto. de Ciências Florestais, UFPR, Curitiba, PR, Brasil - ncrosot@ufpr.br

${ }^{3} E^{2} g^{a}$. Florestal, Dra ., EMBRAPA Florestas, Colombo, PR, Brasil - augusta@cnpf.com.br - yeda@ cnpf.com.br

Recebido para publicação: 04/05/2007 - Aceito para publicação: 06/10/2008

\begin{abstract}
Resumo
Determinou-se a composição, diversidade, estrutura e qualidade do fuste do componente arbóreo presente na Reserva Florestal Embrapa/Epagri, Caçador (SC) (RFEE), de 1.194 hectares, inserida em uma área de Floresta Ombrófila Mista (FOM). Foram alocadas 48 parcelas temporárias de $500 \mathrm{~m}^{2}$ e 8 parcelas de $250 \mathrm{~m}^{2}$, sendo inventariados 1.225 indivíduos com DAP maior ou igual a $10 \mathrm{~cm}$. Calcularam-se diferentes parâmetros fitossociológicos, destacando-se, entre eles, o Valor de Importância Ampliado (VIA). Determinaram-se 71 espécies, 33 famílias e 54 gêneros, sendo as famílias Myrtaceae, Lauraceae, Fabaceae, Flacourtiaceae, Asteraceae, Aquifoliaceae e Sapindaceae as que apresentaram maior riqueza de espécies, representando, juntas, 52,8\% do número total de espécies encontradas. A densidade média foi de 484 árvores/ha, e os valores médios de DAP e altura total foram $23,9 \mathrm{~cm}$ e $11,7 \mathrm{~m}$, respectivamente. A área basal média estimada foi de $31,4 \mathrm{~m}^{2} / \mathrm{ha}$. As dez principais espécies da RFEE, segundo o VIA, foram: Cupania vernalis, Araucaria angustifolia, Ocotea porosa, Capsicodendron dinisii, Prunus brasiliensis, Ocotea pulchella, Clethra scabra, Matayba elaeagnoides, Ocotea puberula e Sebastiania commersoniana. Constatou-se que o padrão florístico que caracteriza as áreas de ocorrência da FOM também é seguido na RFEE, sendo o índice de diversidade de Shannon para espécies de 3,586 nats/ind., e para famílias, de 2,827 nats/ind.

Palavras-chave: Floresta Ombrófila Mista; fitossociologia; valor de importância; diversidade.
\end{abstract}

\begin{abstract}
Floristic analysis and phytosociology of trees from the Mixed Ombrophyllous Forest in the Forest Reserve Embrapa/Epagri in Caçador, SC, Brazil. Composition, diversity, structure and stem quality of trees were determined for the Forest Reserve Embrapa/Epagri (RFEE), Caçador (SC), which consists of a 1,194 ha Mixed Ombrophyllous Forest patch. In forty-eight 0.05 ha sample plots and eight 0.025 sample plots, 1,225 trees with DBH greater than $10 \mathrm{~cm}$ were identified and measured. Phytosociological indices were also calculated, including the Extended Importance Value (EIV). Seventy-one tree species, 33 families and 54 genera were found on the area. Species richness concentrated on Myrtaceae, Lauraceae, Fabaceae, Flacourtiaceae, Asteraceae, Aquifoliaceae and Sapindaceae families, which together accounted for $52.8 \%$ of the total number of species. Average density was 484 trees/ha and average DBH and total height were $23.9 \mathrm{~cm}$ and $11.7 \mathrm{~m}$, respectively. Estimated basal area was $31.4 \mathrm{~m}^{2} / \mathrm{ha}$. According to the EIV, the ten main tree species of the RFEE were: Cupania vernalis, Araucaria angustifolia, Ocotea porosa, Capsicodendron dinisii, Prunus brasiliensis, Ocotea pulchella, Clethra scabra, Matayba elaeagnoides, Ocotea puberula and Sebastiania commersoniana. The typical floristic pattern of the Mixed Ombrophyllous Forest is similar to the one observed in the RFEE. The Shannon Diversity Index was equal to 3.586 nats/ind. for species and 2.827 nats/ind. for families.

Keywords: Mixed Ombrophyllous Forest; phytosociology; importance value; diversity.
\end{abstract}

\section{INTRODUÇÃO}

A Floresta Ombrófila Mista (FOM), também conhecida como "floresta com araucária" ou como “mata-de-araucária ou pinheiral”, é uma vegetação típica do Planalto Meridional (IBGE, 1991). A área de 
ocorrência da araucária era de aproximadamente 20 milhões de hectares no Brasil, ou seja, quatro vezes a superfície do estado de Santa Catarina (REITZ et al., 1978). No início do século XX, cerca de 35\% da cobertura vegetal dos estados do Sul do Brasil eram representados pela FOM, mas hoje, pelo intenso processo de exploração, as reservas naturais da floresta com araucária encontram-se limitadas a valores estimados entre 2 e 4\% da área original (PUCHALSKI et al., 2006). Segundo Leite (1994), a FOM hoje encontra-se reduzida a $20.000 \mathrm{~km}^{2}$, sendo a causa principal dessa redução de cobertura florestal o desmatamento desenfreado para a expansão da agricultura e da pecuária (SANQUETTA et al., 2002).

A FOM é uma unidade fitoecológica que contempla a "coexistência de representantes das floras tropical (afrobrasileira) e temperada (austrobrasileira), em marcada relevância fisionômica de elementos Coniferales e Laurales" (RODERJAN et al., 2002), onde domina Araucaria angustifolia (araucária, pinheiro-do-paraná). Segundo IBGE (1991), a presença de gêneros primitivos, como Drymis e Araucaria (Australásicos) e Podocarpus (Afro-Asiático) sugere, em face da altitude e da latitude do Planalto Meridional, uma ocupação recente, a partir de refúgios altomontanos, apresentando quatro formações diferentes: Aluvial, Submontana, Montana e Altomontana.

No estado de Santa Catarina, as florestas com araucária se distribuíam por quase todo o planalto, sendo, porém, interrompidas a cada passo pelos campos naturais, que formavam ilhas de tamanhos diferentes (KLEIN, 1960). Atualmente, restam apenas pequenos núcleos dessas florestas e o espaço florestal encontra-se, em sua maioria, coberto por formações secundárias ou por florestas degradadas pela retirada de espécies comerciais do seu interior (REIS, 1993).

Reis (1993) também comentou que o número de espécies comuns à FOM e à Floresta Ombrófila Densa alcança 146 espécies, enquanto o número de espécies comuns com a Floresta Estacional Decidual é de 87 espécies.

Klein (1960) menciona que "a vegetação da região da araucária não constitui, como pode parecer à primeira vista, uma formação homogênea e contínua. É formada por múltiplas associações e agrupamentos, que se encontram nos mais variados estágios de sucessão". O autor denominou essa vegetação de "Formação de Araucária", não tanto em virtude da dominância fitofisionômica de Araucaria angustifolia na maior parte das associações e que, por vezes, dá a impressão de tratar-se de uma associação pura, mas mais pelo alto valor econômico que essa espécie representa para o Brasil, embora "apenas domine nos estágios pioneiros, sendo, nas demais associações mais evoluídas, sua dominância não dinâmica, mas somente fisionômica".

Para conservar esses remanescentes e utilizá-los adequadamente, é necessário conhecer sua composição florística e sua estrutura, vertical e horizontal, pois esses dados permitem fazer deduções sobre a origem, características ecológicas e sinecológicas, dinâmica e tendência do futuro desenvolvimento das florestas (LONGHI, 1980), conhecimentos básicos para a aplicação de sistemas silviculturais que se ajustem ecologicamente bem a esse tipo de formação vegetal. Para Silva e Scariot (2003), estudos fitossociológicos, florísticos e estruturais de remanescentes florestais são extremamente importantes, sendo o ponto inicial para a adoção de critérios e metodologias visando seu manejo, conservação e recuperação.

A estrutura horizontal diz respeito à distribuição espacial de todas as espécies que compõem uma comunidade, e a estrutura vertical refere-se ao arranjo das diferentes sinúsias que integram uma comunidade vegetal (GALVÃO, 2005). Em diversas florestas nota-se com frequência uma diferenciação vertical ou estratificação, que, segundo Whittaker (1975), é determinada, principalmente, pela resposta ao decréscimo da disponibilidade de luz ao longo do perfil vertical da floresta.

A posição sociológica (PS) das árvores (ou estrutura vertical da floresta) é um parâmetro normalmente empregado em levantamentos fitossociológicos. Vários autores mencionam que é recomendável considerar a PS em estudos estruturais das florestas, conhecida também como "expansão vertical" das espécies na definição de Lamprecht (1964), além dos parâmetros de estrutura horizontal, pois as espécies ficam mais corretamente situadas na ordem ecológica que lhes corresponde, o que permite uma planificação silvicultural das florestas sobre bases mais reais (FINOL, 1971; GALVÃO, 2005). Nesse sentido, Finol (1971) menciona "que os estudos efetuados por Curtis e McIntosh, que propõem o valor de importância como a soma da densidade, dominância e frequência relativas, verdadeiramente não permitem uma informação completa sobre as florestas tropicais, devido a que incorporam apenas a análise da estrutura horizontal, o que não reflete cabalmente o que verdadeiramente caracteriza as florestas: sua grande heterogeneidade e sua grande irregularidade". 
O presente trabalho teve como objetivos analisar a composição florística e a estrutura fitossociológica do estrato arbóreo de um fragmento de Floresta Ombrófila Mista localizado em Caçador (SC).

\section{MATERIAL E MÉTODOS}

Este estudo foi realizado na Reserva Florestal Embrapa/Epagri (RFEE), localizada ao sudeste do

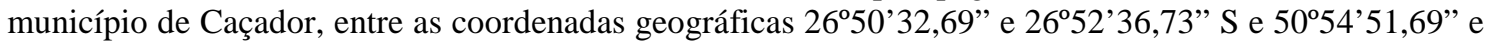
$51^{\circ} 58^{\prime} 40,36$ " O, região centro-oeste do estado de Santa Catarina. A reserva compreende uma área de 1.194 hectares (KURASZ, 2005).

A cobertura vegetal existente na RFEE é constituída por um dos últimos remanescentes da Floresta Ombrófila Mista, onde se destacam algumas das espécies que constam na lista oficial de espécies ameaçadas de extinção (IBAMA, 1992), tais como Araucaria angustifolia (araucária), Ocotea porosa (imbuia) e Ocotea catharinensis (canela-preta), todas na categoria "vulnerável". A altitude na reserva varia de 920 a 1.075 metros s.n.m., enquadrando-se esta floresta, portanto, em uma formação de FOM Montana.

O clima da área de estudo é mesotérmico, do tipo Cfb (subtropical úmido sem estação seca), segundo a classificação climática de Köppen, isto é, temperado úmido com uma média de 26 geadas por ano (KURASZ, 2005). A temperatura média anual é de $16,6^{\circ} \mathrm{C}$, com máxima e mínima média de 22,5 e $11^{\circ} \mathrm{C}$, respectivamente. A precipitação média anual é de $1.613 \mathrm{~mm}$ (DLUGOSZ et al., 2005). O relevo da RFEE pode se caracterizar como plano a moderadamente ondulado, com exposições preferencialmente nas direções norte e oeste. Os solos se distribuem em quatro ordens: Cambissolos, Gleissolos, Nitossolos e Neossolos. A acidez é extremamente alta em quase todos ( $\mathrm{pH}<4,3$ ) (KURASZ et al., 2004).

Para o levantamento florístico e a análise fitossociológica, utilizou-se o método de parcelas múltiplas (MUELLER-DOMBOIS; ELLENBERG, 1974), sendo estabelecidas 48 parcelas de $500 \mathrm{~m}^{2}$ cada e 8 parcelas de $250 \mathrm{~m}^{2}$ cada, totalizando 56 parcelas e 2,6 ha amostrados. As parcelas foram distribuídas de forma proporcional à área ocupada por 13 classes de exposição/declividade previamente determinadas, de forma aleatória dentro de cada classe. O critério foi alocar as parcelas de menor tamanho no estágio inicial, devido ao grande número de árvores desse estágio e à sua baixa diversidade florística, em comparação com os estágios médio e avançado, o que permitiu, ao se utilizar parcelas de menor tamanho, economizar tempo e custo sem se alterar os coeficientes de variação das variáveis medidas nem a representatividade da florística, situações que estão mais influenciadas pelo número de repetições utilizadas que pelo tamanho da parcela (SIMPLÍCIO, 1978; RIVERA et al., 2002).

Em cada parcela do inventário foram consideradas, para as árvores com DAP acima de $10 \mathrm{~cm}$ (ou 31,4 cm de CAP-Circunferência à Altura do Peito), as seguintes variáveis: CAP, altura total, posição sociológica e forma e sanidade do fuste. Coletou-se, sempre que necessário, material botânico para identificação das espécies e posterior herborização. O material foi identificado com o auxílio de especialistas do Museu Botânico Municipal de Curitiba (MBM) e do Departamento de Ciências Florestais da UFPR. Os nomes das famílias, espécies e autores baseiam-se nos nomes encontrados no banco eletrônico do Missouri Botanical Garden (www.mobot.org).

Foi realizada uma análise do número de espécies por gênero e família. Para se determinar se o esforço amostral foi suficiente para representar adequadamente a comunidade da RFEE, foi analisada a curva "espécie/área" (ou "do coletor"). Além da análise dessa curva, obteve-se o índice de espécies raras (IER), que também fornece uma indicação da suficiência e representatividade da amostragem (GALVÃO et al., 2002).

Para expressar a estrutura horizontal da comunidade vegetal existente na RFEE, foram determinados os seguintes parâmetros: densidade, dominância e frequência (tanto relativa como absoluta), valor de cobertura, porcentagem de cobertura, valor de importância e porcentagem de importância. A estrutura vertical foi analisada por meio do comportamento das espécies que compõem a comunidade estudada, segundo a variável posição sociológica, considerando-se três estratos: superior, médio e inferior, conforme definidos por Lamprecht (1964). Foram calculadas a PS absoluta e relativa por espécie e por família, já que cada indivíduo no campo foi analisado segundo essa variável, empregando-se com esse propósito a metodologia de Longhi (1980). 
O valor de importância ampliado (VIA) é um parâmetro que utiliza tanto a estrutura horizontal como a vertical. Neste trabalho foi adicionado como parâmetro vertical a posição sociológica, mas não a regeneração natural, devido a que esta última não foi medida no levantamento de dados. A expressão para calculá-lo foi a seguinte: VIA = estrutura horizontal + estrutura vertical; ou, de forma equivalente, VIA = $\mathrm{VI}+\mathrm{PSR}$, em que VI = valor de importância, $\mathrm{VI}$ = densidade relativa $(\mathrm{DR})+$ frequência relativa $(\mathrm{FR})$ + dominância relativa (DoR) e PSR = posição sociológica relativa. Se o VIA for dividido por quatro, obtém-se esse valor em porcentagem, conhecido como porcentagem de importância ampliado (PIA).

Para o cálculo da diversidade, usou-se o índice de diversidade de Shannon (H'), tanto para espécies como para famílias. Os parâmetros fitossociológicos empregados nesta pesquisa baseiam-se em Lamprecht (1964), Finol (1971), Mueller-Dombois; Ellenberg (1974), Longhi (1980), Rodal et al. (1992), Galvão (2005) e Gomide et al. (2005). O cálculo dos dados e a representação gráfica foi realizada com o software Microsoft Excel 2002.

Efetuou-se uma análise da qualidade do fuste através da interpretação das classes de forma e sanidade para todas as árvores das parcelas inventariadas. Utilizaram-se três níveis, tanto para a forma como para a sanidade, definidos segundo Galvão (2005). A inclusão das árvores nos diferentes níveis foi realizada por observação visual, procurando-se analisar o estado dos respectivos parâmetros (LONGHI, 1980).

Os fatores forma e sanidade foram combinados em uma matriz de dupla entrada (3x3), com o objetivo de gerar uma regra que permitisse definir as classes de qualidade do fuste de todas as árvores. Essa regra baseou-se no trabalho de Rivera et al. (2002) e foi adaptada para esta pesquisa, conforme apresentando na tabela 1.

Tabela 1. Regra para a definição da qualidade do fuste para a Reserva Florestal EMBRAPA/EPAGRI. Table 1. Definition rules for stem quality evaluation for the Forest Reserve EMBRAPA/EPAGRI.

\begin{tabular}{llcl}
\hline \multirow{2}{*}{ Forma } & \multicolumn{3}{c}{ Sanidade } \\
\cline { 2 - 4 } & $\mathbf{1}$ & $\mathbf{2}$ & $\mathbf{3}$ \\
\hline 1 & 1 & 2 & 3 \\
2 & 2 & 2 & 3 \\
3 & 3 & 3 & 3 \\
\hline Onde: 1: boa; 2: média; 3: má. & &
\end{tabular}

\section{RESULTADOS E DISCUSSÃO}

Foram identificadas 71 espécies, distribuídas em 54 gêneros e 33 famílias botânicas (Tabela 2). As famílias que apresentaram maior riqueza de espécies foram Myrtaceae (14), Lauraceae e Fabaceae (5), Flacourtiaceae e Asteraceae (4), Aquifoliaceae e Sapindaceae (3), que representaram 52,8\% do número total de espécies encontradas. Sete famílias tiveram duas espécies, e 20, apenas uma espécie. Nos trabalhos desenvolvidos em Floresta Ombrófila Mista nos estados do Paraná, Santa Catarina e Rio Grande do Sul, por Longhi (1980), Oliveira e Rotta (1982), Silva e Marconi (1990), Negrelle e Silva (1992), Rondon Neto et al. (2002a) e Kozera et al. (2006), as principais famílias são semelhantes às principais famílias encontradas neste estudo, confirmando-se o padrão florístico que caracteriza essa formação florestal.

Tabela 2. Relação de famílias e espécies arbóreas encontradas na Reserva Florestal EMBRAPA/EPAGRI, Caçador, SC - Brasil.

Table 2. Families and tree species of the Forest Reserve EMBRAPA/EPAGRI, Caçador, SC - Brazil.

\begin{tabular}{llc}
\hline Família & Espécie & Nome comum \\
\hline Anacardiaceae & Lithraea brasiliensis Marchand & Bugreiro \\
& Schinus terebinthifolius Raddi & Aroeira \\
Aquifoliaceae & Ilex dumosa Reissek & Congonha \\
& Ilex paraguariensis A. St.-Hil. & Erva-mate \\
& Ilex theazans Mart. & Caúna \\
Araliaceae & Oreopanax fulvum Marchal & Figueira-do-mato \\
Araucariaceae & Araucaria angustifolia (Bertol.) Kuntze & Araucária \\
\hline
\end{tabular}




\begin{tabular}{|c|c|c|}
\hline Arecaceae & Syagrus romanzoffiana (Cham.) Glassman & Jerivá \\
\hline \multirow[t]{4}{*}{ Asteraceae } & Baccharis brachylaenoides DC. & Vassourinha \\
\hline & Baccharis microdonta DC. & Vassoura-tupichava \\
\hline & Piptocarpha angustifolia Dusén ex Malme & Vassourão-branco \\
\hline & Vernonia discolor (Spreng.) Less. & Vassourão-preto \\
\hline Bignoniaceae & Jacaranda puberula Cham. & Caroba / Jacarandá \\
\hline Canellaceae & Capsicodendron dinisii (Schwacke) Occhioni & Pimenteira \\
\hline \multirow[t]{2}{*}{ Celastraceae } & Maytenus evonymoides Reissek & Coração-de-bugre \\
\hline & Maytenus sp. & \\
\hline Clethraceae & Clethra scabra Pers. & Carne-de-vaca \\
\hline \multirow[t]{2}{*}{ Cunoniaceae } & Lamanonia speciosa (Cambess.) L.B. Sm. & Guaraperê \\
\hline & Weinmannia paulliniifolia Pohl & Gramimunha \\
\hline Elaeocarpaceae & Sloanea monosperma Vell. & Sapopema \\
\hline Erythroxylaceae & Erythroxylum deciduum A. St.-Hil. & Cocão \\
\hline \multirow[t]{2}{*}{ Euphorbiaceae } & Sapium glandulatum (Vell.) Pax & Leiteiro / Pau-de-leite \\
\hline & Sebastiania commersoniana (Baill.) L.B. Sm. \& Downs & Branquilho \\
\hline \multirow[t]{5}{*}{ Fabaceae } & Inga lentiscifolia Benth. & Ingá \\
\hline & Inga sessilis (Vell.) Mart. & Ingá \\
\hline & Inga virescens Benth. & Ingá \\
\hline & Lonchocarpus campestris Mart. ex Benth. & Rabo-de-macaco \\
\hline & Mimosa scabrella Benth. & Bracatinga \\
\hline \multirow[t]{4}{*}{ Flacourtiaceae } & Banara tomentosa Clos. & Guaçatunga / Cambroé \\
\hline & Casearia decandra Jacq. & Guaçatunga \\
\hline & Casearia obliqua Spreng. & Guaçatunga \\
\hline & Xylosma ciliatifolia (Clos.) Eichler & Sucará \\
\hline \multirow[t]{5}{*}{ Lauraceae } & Cinnamomum vesiculosum (Nees) Kosterm. & Pau-d'alho \\
\hline & Ocotea catharinensis $\mathrm{Mez}$ & Canela-preta \\
\hline & Ocotea porosa (Nees \& C. Mart.) Barroso & Imbuia \\
\hline & Ocotea puberula (Rich.) Nees & Canela-guaicá \\
\hline & Ocotea pulchella (Nees) Mez & Canela-lajeana \\
\hline Loganiaceae & Strychnos brasiliensis (Spreng.) Mart. & Esporão-de-galo \\
\hline Meliaceae & Cedrela fissilis Vell. & Cedro / Cedro-rosa \\
\hline \multirow[t]{2}{*}{ Myrsinaceae } & Myrsine coriacea (Sw.) R. Br. ex Roem. \& Schult. & Capororoquinha \\
\hline & Myrsine umbellata Mart. & Capororocão / Capororoca \\
\hline \multirow[t]{14}{*}{ Myrtaceae } & Blepharocalyx salicifolius (Kunth) O. Berg & Guamirim \\
\hline & Calyptranthes concinna DC. & Guamirim-facho \\
\hline & Campomanesia guazumifolia (Cambess.) O. Berg & Sete-capotes \\
\hline & Campomanesia xanthocarpa $\mathrm{O}$. Berg & Guabirova \\
\hline & Eugenia handroana D. Legrand & Guamirim-vermelho \\
\hline & Eugenia pyriformis Cambess. & Uvaia \\
\hline & Myrceugenia euosma (O. Berg) D. Legrand & Cambuí \\
\hline & Myrceugenia miersiana (Gardner) D. Legrand \& Kausel & Guaraitá \\
\hline & Myrceugenia myrcioides (Cambess.) O. Berg & Caingá / Guamirim-branco \\
\hline & Myrceugenia ovata var. regnelliana (O. Berg) Landrum & Cambuí \\
\hline & Myrcia laruotteana var. paraguayensis $\mathrm{O}$. Berg & Camboí / Pitanga \\
\hline & Myrcianthes gigantea (D. Legrand) D. Legrand & Guabijú \\
\hline & Myrciaria tenella (DC.) O. Berg & Cambuí \\
\hline & Psidium cattleianum Sabine & Araçá \\
\hline
\end{tabular}




\begin{tabular}{llc}
\hline Proteaceae & Roupala brasiliensis Klotzsch & Carvalho \\
Rosaceae & Prunus brasiliensis (Cham. \& Schltdl.) Dietrich & Pessegueiro-bravo \\
Rubiaceae & Coutarea hexandra (Jacq.) K. Schum. & Quina / Quineira \\
Rutaceae & Zanthoxylum rhoifolium Lam. & Mamica-de-porca / Juvevê \\
Sapindaceae & Allophylus edulis (A. St.-Hil., Cambess. \& A. Juss.) Radlk. & Vacum \\
& Cupania vernalis Cambess. & Camboatá / Cuvatã \\
Simaroubaceae & Patayba elaeagnoides Radlk. & Miguel-pintado \\
Solanaceae & Solanum erianthum D. Don & Pau-tenente / Timbó \\
& Solanum sanctae-katharinae Dunal & Fumeiro \\
Styracaceae & Styrax leprosus Hook. \& Arn. & Fumo-bravo \\
Symplocaceae & Symplocos tenuifolia Brand & Cajujo / Farinha-seca \\
Tiliaceae & Luehea divaricata Mart. & Maria-mole \\
Verbenaceae & Citharexylum solanaceum Cham. & Açoita-cavalo \\
& Vitex megapotamica (Spreng.) Moldenke & Tarumã-pequeno \\
Winteraceae & Drimys brasiliensis Miers & Tarumã \\
Z-desconhecida & Z-Desconhecida 1 & Cataia \\
\hline
\end{tabular}

Quando se analisou a densidade de espécies que participam dessa formação florestal, determinou-se que existem 483,6 indivíduos por hectare, sendo 21 espécies as que em conjunto somam $75 \%$ desse total. Cupania vernalis é a espécie dominante, com 75 indivíduos/ha (14,5\%), seguida por Capsicodendron dinisii, Prunus brasiliensis, Ocotea pulchella, Araucaria angustifolia e Matayba elaeagnoides, que apresentaram entre 20 e 30 indivíduos por hectare. As demais 51 espécies acumularam apenas $25 \%$ do total de indivíduos por hectare.

Cinco famílias acumularam 51,3\% do número de indivíduos por hectare: Sapindaceae (20,0\%), Lauraceae (11,4\%), Myrtaceae (8,7\%), Canellaceae $(5,7 \%)$ e Anacardiaceae $(5,5 \%)$.

Foi possível constatar que, dentre as 21 espécies que representam $75 \%$ do total de árvores, várias são indicadoras de ação antrópica, como Lithraea brasiliensis, Piptocarpha angustifolia, Schinus terebinthifolius e Vernonia discolor. Esse fato, somado à baixa presença de Cedrela fissilis, Vitex megapotamica, Myrcianthes gigantea e Blepharocalyx salicifolius, espécies comercialmente importantes e típicas da formação de araucária (LONGHI, 1997), apoiaria a história de antigas intervenções efetuadas na RFEE.

Na figura 1 apresenta-se a curva espécie/área (curva do coletor), na qual se observa que o número de espécies adicionais cumulativamente amostradas aumenta conforme o número de parcelas amostradas aumenta, existindo uma estabilização da curva a partir da parcela $42\left(20.000 \mathrm{~m}^{2}\right.$ ou $\left.2 \mathrm{ha}\right), \mathrm{o}$ que indica que a maior parte das espécies foi amostrada (quadro com linha tracejada nessa figura).

Calculou-se o IER. Um valor alto (30\%) para esse índice significa que existe uma tendência de que espécies deixem de ser amostradas em função de sua raridade de ocorrência. Para este trabalho, o valor obtido foi de $9,7 \%$, o que também apoia a suficiência do processo amostral.

O valor médio de DAP para toda a floresta foi de $23,9 \mathrm{~cm}$. Longhi (1997) obteve praticamente o mesmo valor médio $(23,7 \mathrm{~cm})$ em uma amostragem de seis grupos florísticos pertencentes a uma área de FOM no Rio Grande do Sul, para indivíduos com DAP superior a 9,5 cm. Apenas três espécies (Araucaria angustifolia, Ocotea porosa e Vitex megapotamica) superaram $40 \mathrm{~cm}$ de DAP médio. A grande maioria das espécies (43) tem sua média de DAP abaixo de $30 \mathrm{~cm}$ e principalmente concentrada na faixa de 10 a $20 \mathrm{~cm}$ de DAP.

Na figura 2 pode ser observada a distribuição dos indivíduos por classes diamétricas para toda a floresta. A curva que se descreve apresenta a característica própria de florestas naturais multietâneas, em uma distribuição conhecida como "J" invertido, na qual a maior frequência dos indivíduos encontra-se nos diâmetros menores, o que, segundo Longhi (1980), resulta ser altamente positivo e "constitui a melhor garantia para a existência e sobrevivência da associação florestal climácica em questão". Outras pesquisas, como as de Da Croce (1991) na mesma área deste estudo, de Silva; Marconi (1990) e Rondon Neto et al. (2002a) no Paraná, a de Rondon Neto et al. (2002b) no Rio Grande do Sul e a de Jarenkow 
(1994) no Vale do Sul (RS), revelaram o mesmo tipo de distribuição diamétrica que a determinada neste trabalho.

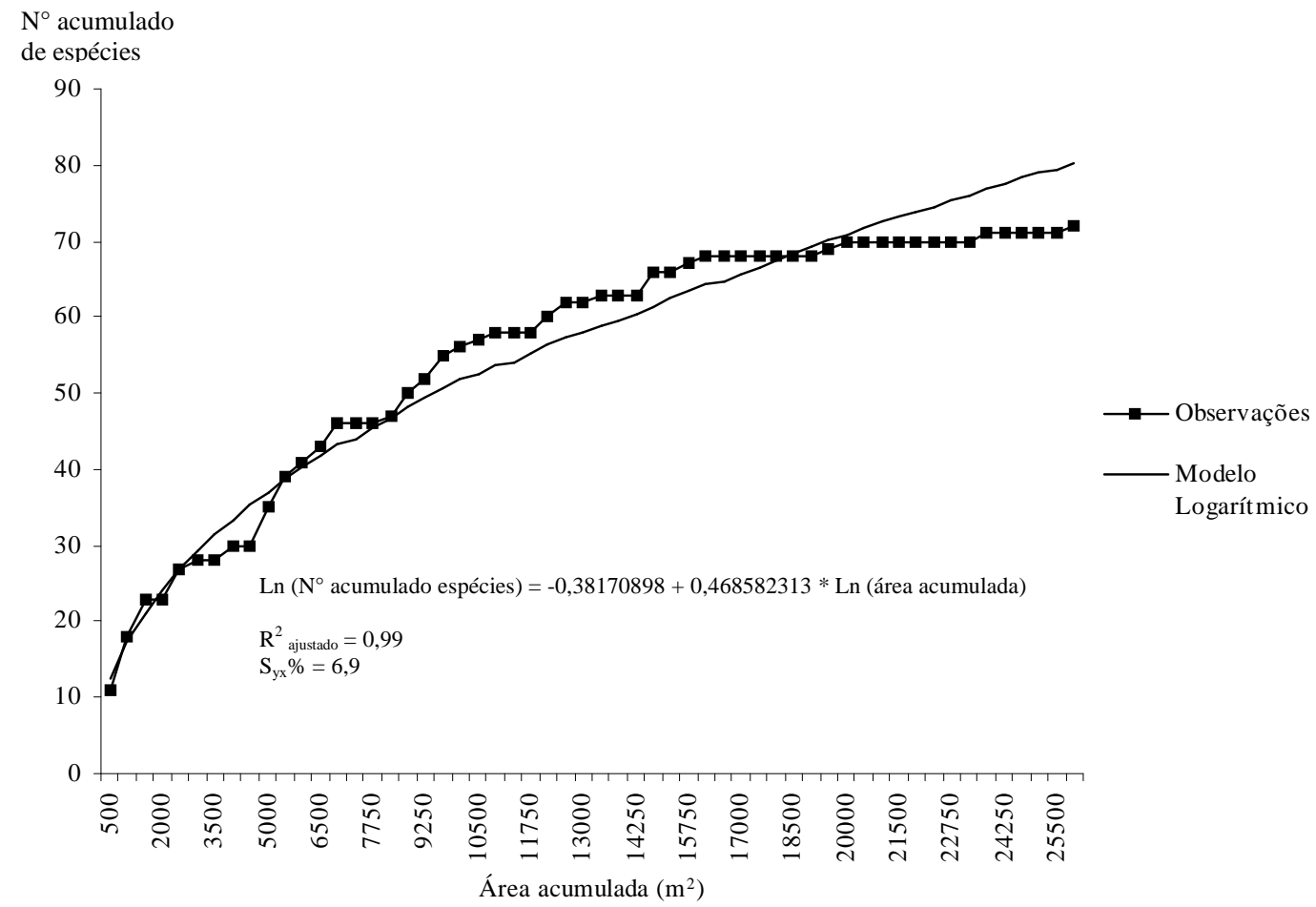

Figura 1. Curva espécie/área (curva do coletor) para a Reserva Florestal EMBRAPA/EPAGRI, Caçador, $\mathrm{SC}-$ Brasil.

Figure 1. Species-area curve (collector's curve) for the Forest Reserve EMBRAPA/EPAGRI, Caçador, $\mathrm{SC}-$ Brazil.

Nas classes maiores, observou-se uma densidade muito baixa de indivíduos por hectare $(0,4)$, razão pela qual não aparecem na figura 2 (em função da escala), embora existam indivíduos nessas classes.

A maioria das espécies concentrou seus diâmetros nas classes inferiores. No entanto, o padrão seguido por algumas espécies foi diferente do "J" invertido, quando se analisou a distribuição diamétrica por espécie (Figura 3).

Por exemplo, Araucaria angustifolia apresentou uma distribuição multimodal, que se caracteriza por possuir mais de um ponto de maior frequência, típica de florestas que sofreram exploração, sendo modificadas certas classes de diâmetro, geralmente as intermediárias e maiores. Atualmente existem indivíduos em todas as classes de diâmetro, sendo o número nas classes menores próximo a $25 \%$ do total de indivíduos, o que é desejável, uma vez que permite que árvores dessa espécie continuem participando da dinâmica natural nessa formação, embora esse número não garanta sua participação nas classes diamétricas superiores se a espécie não conseguir vencer a concorrência natural das outras espécies. Ocotea porosa segue um padrão algo assemelhado ao de curva normal com assimetria negativa. Os padrões encontrados para essas duas espécies no trabalho de Negrelle e Silva (1992), desenvolvido na mesma área, foram bastante semelhantes aos desta pesquisa, devido a não existir atividades de exploração desde a década de 1960. Prunus brasiliensis, Capsicodendron dinisii, Ocotea pulchella e Cupania vernalis apresentaram o mesmo tipo de curva que aquela opontada para todos os indivíduos da comunidade, mas com algumas distorções em algumas classes. 


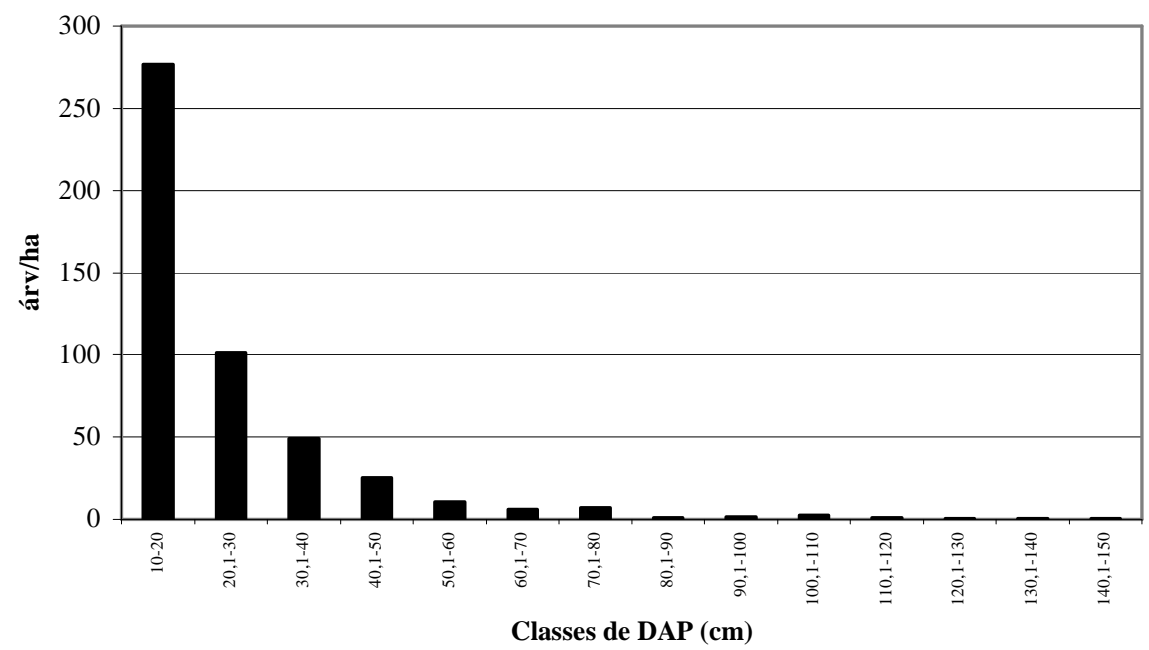

Figura 2. Distribuição do número de árvores por hectare por classes diamétricas para toda a floresta da Reserva Florestal EMBRAPA/EPAGRI, Caçador, SC - Brasil.

Figure 2. Distribution of number per trees per hectare per diameter class for the whole forest of the Forest Reserve EMBRAPA/EPAGRI, Caçador, SC - Brazil.

A área basal média para este estudo foi de $31,4 \mathrm{~m}^{2} / \mathrm{ha}$, valor baixo em função do grande número de indivíduos com diâmetros finos. Esse valor foi muito semelhante ao encontrado por Oliveira e Rotta (1982), que obtiveram 30,4 m²/ha em uma área de FOM no Paraná. Segundo Longhi (1997), as florestas primárias registram valores superiores a $35 \mathrm{~m}^{2} / \mathrm{h}$. Esse autor determinou uma área basal média de 22,1 $\mathrm{m}^{2} /$ ha para seis grupos florísticos em uma área de FOM do Rio Grande do Sul, indicando que esse valor baixo é uma evidência de que se trata de fases secundárias.

A área basal média por árvore e por espécie concentrou-se em valores abaixo de $0,1 \mathrm{~m}^{2}$ (obtevese uma média de $0,067 \mathrm{~m}^{2} / a ́ r v$ para todas ás árvores inventariadas), exceto para Araucaria angustifolia e Ocotea porosa, que superaram os 0,4 e $0,2 \mathrm{~m}^{2} /$ árv, respectivamente.

Como mostra a figura 4, a maior concentração de área basal encontra-se nas classes inferiores e intermediárias, logicamente porque nessas classes o número de árvores foi superior ao das classes superiores.

Ao observar a distribuição de área basal para a floresta como um todo, é possível ver que ela pode se assimilar a uma curva com tendência decrescente, na qual algumas classes apresentaram distorções dessa tendência (50,1-60; 60,1-70; 80,1-90; 90,1-100; 110,1-120; 120,1-130 e 130,1-140). Isso deve-se à pouca quantidade de estoque $\left(\mathrm{m}^{2}\right)$, e coincide com as classes que apresentaram distorções nas distribuições diamétricas das espécies Ocotea porosa e Araucaria angustifolia, em que as árvores são poucas ou não existem (Figura 3). Esse fato vem corroborar a forte exploração sofrida por essas espécies, de alto valor madeireiro, em áreas de floresta com araucária e particularmente na RFEE. Segundo Da Croce (1991), essas duas espécies florestais marcaram decididamente o ciclo da madeira, que foi a base econômica da região oeste e centro-oeste do estado de Santa Catarina.

Com relação ao número de ocorrências das espécies nas parcelas, parâmetro denominado comumente como frequência, sete espécies foram encontradas em mais de 30\% das 56 parcelas alocadas. Cupania vernalis e Ocotea porosa estiveram presentes em mais de $50 \%$ das parcelas (31 e 28 parcelas, respectivamente), enquanto que Ocotea pulchella e Araucaria angustifolia em mais de $40 \%$ (27 e 24 parcelas, respectivamente) e Capsicodendron dinisii, Clethra scabra e Sebastiania commersoniana, com 21, 20 e 18 parcelas, respectivamente, em mais de $30 \%$. 


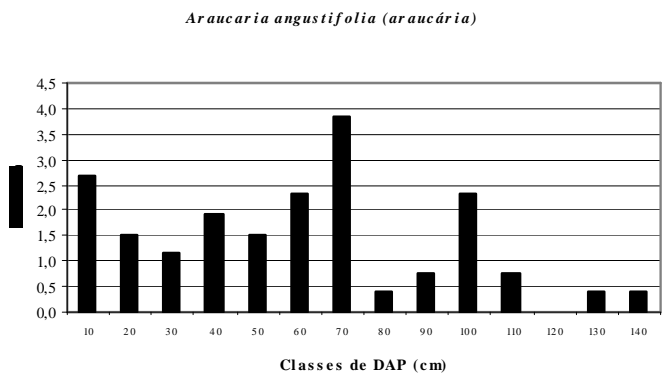

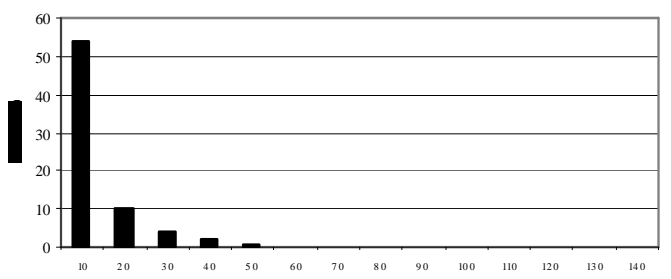

Classe de DAP (cm)

Ocotea porosa (imbuia)

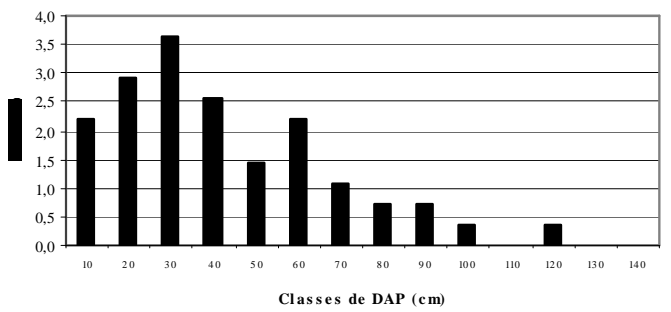

Prunus brasiliensis (pessegueiro-bravo)

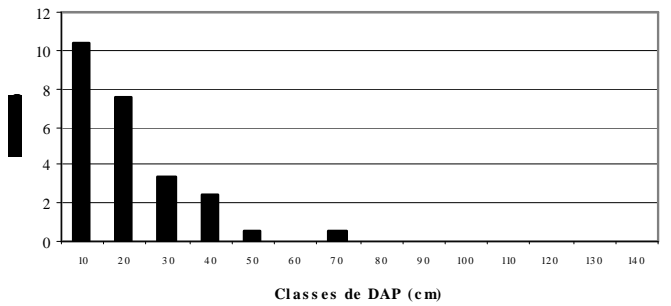

Capsicodendron dinisii (pimenteira)

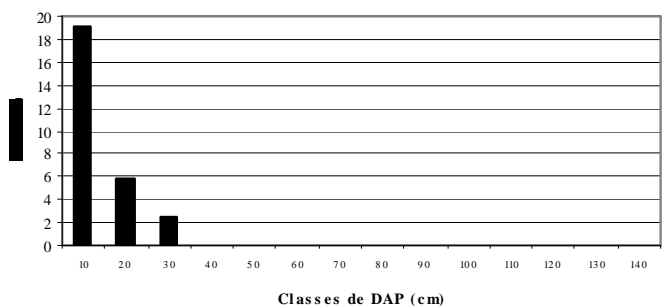

Ocotea pulchella (canela-lajeana)

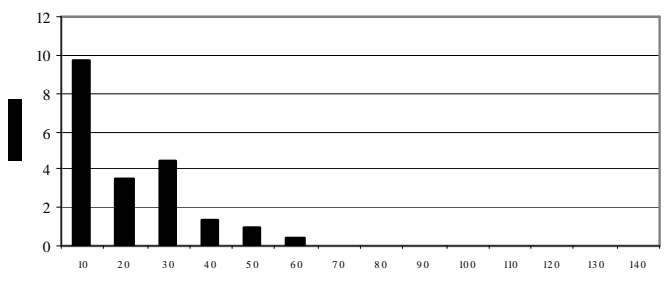

Classes de DAP (cm)

Figura 3. Distribuições do número de árvores/ha por classes de diâmetro para seis espécies da Reserva Florestal EMBRAPA/EPAGRI, Caçador, SC - Brasil.

Figure 3. Distribution of number per trees per hectare per diameter class for six species of the Forest Reserve EMBRAPA/EPAGRI, Caçador, SC - Brazil.

Determinou-se, para cada árvore da amostra, a posição sociológica em três estratos: superior, médio e inferior. Na figura 5 apresentam-se as dez espécies com as maiores posições sociológicas relativas (PSR).

Finol (1971) menciona que "quanto mais regular seja a distribuição dos indivíduos de uma espécie na estrutura vertical de uma floresta (diminuição gradual do número de árvores à medida que se sobe do estrato inferior ao superior), tanto maior será seu valor na posição sociológica relativa".

Pode-se observar, na figura 5, que, dessas dez espécies, Araucaria angustifolia teve a distribuição vertical menos regular e, portanto, a mais baixa PSR, já que o número de árvores no estrato médio e inferior foi muito menor que o número de árvores de seu estrato superior (oito vezes menor). Por outro lado, a espécie com a maior PSR foi Cupania vernalis, que apresentou uma distribuição vertical regular. Apesar da distribuição de Ocotea pulchella e Ocotea porosa não ser propriamente regular, essas espécies tiveram números de árvores, nos estratos médio e inferior, tais que, ao serem somados, foram iguais ou maiores que o número de árvores do estrato superior, permitindo-lhes estarem classificadas entre as dez espécies com maior PSR. 


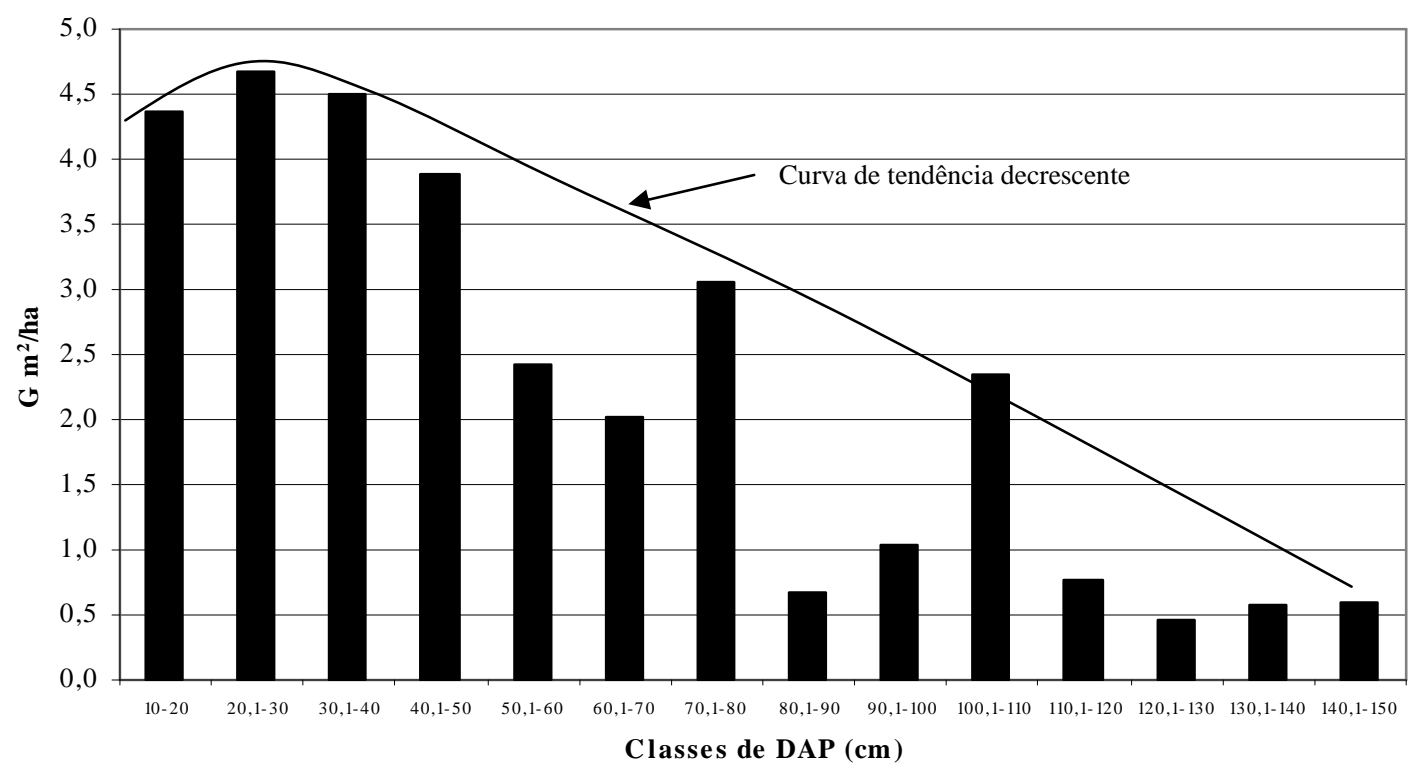

Figura 4. Distribuição da área basal (G) em $\mathrm{m}^{2} /$ ha por classes diamétricas para a Reserva Florestal EMBRAPA/EPAGRI, Caçador, SC - Brasil.

Figure 4. Distribution of basal area $(\mathrm{G})$ in $\mathrm{m}^{2} / \mathrm{ha}$ per diameter class for the Forest Reserve EMBRAPA/EPAGRI, Caçador, SC - Brazil.

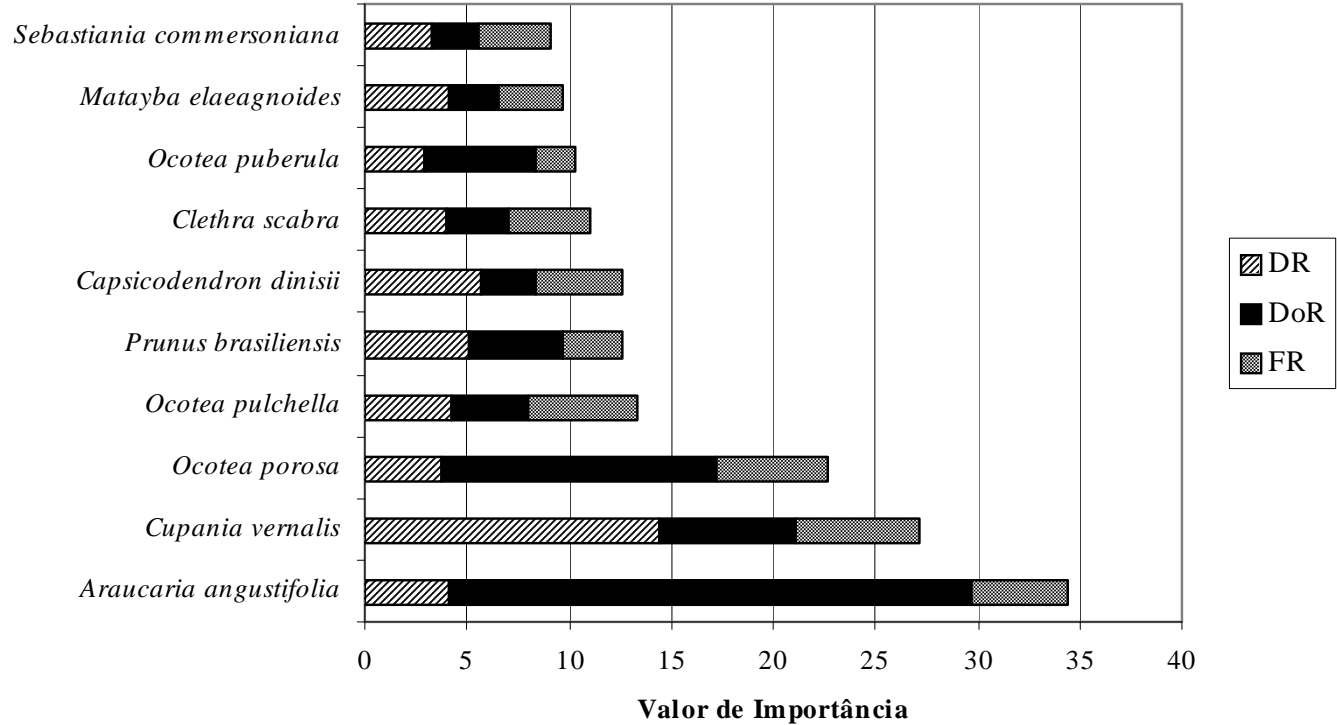

Figura 5. Posição sociológica segundo estratos das dez espécies com maior PSR na Reserva Florestal EMBRAPA/EPAGRI, Caçador, SC - Brasil.

Figure 5. Social class per stratum for the ten species with highest relative social class position in the Forest Reserve EMBRAPA/EPAGRI, Caçador, SC - Brazil.

O número de árvores por hectare, segundo a posição sociológica, foi aproximadamente 126, 189 e 169 para os estratos superior, médio e inferior, respectivamente. 
Observam-se, na figura 6, os valores de importância das dez espécies que obtiveram os maiores resultados, tendo a Araucaria angustifolia o valor mais alto de VI $(34,4)$, seguida de Cupania vernalis $(27,2)$. A alta dominância relativa (DoR) e a alta densidade relativa (DR), respectivamente, obtidas por essas duas espécies, foram os fatores determinantes para que ambas fossem classificadas como as duas principais espécies. Também é interessante ressaltar que três das cinco Lauráceas encontradas na RFEE fizeram parte desse grupo: Ocotea porosa e Ocotea puberula, por seus bons valores em dominância, 4,2 e $1,7 \mathrm{~m}^{2} / \mathrm{ha}$, respectivamente, e Ocotea pulchella, por sua alta frequência, uma vez que foi encontrada em $27(48,2 \%)$ do total de parcelas alocadas.

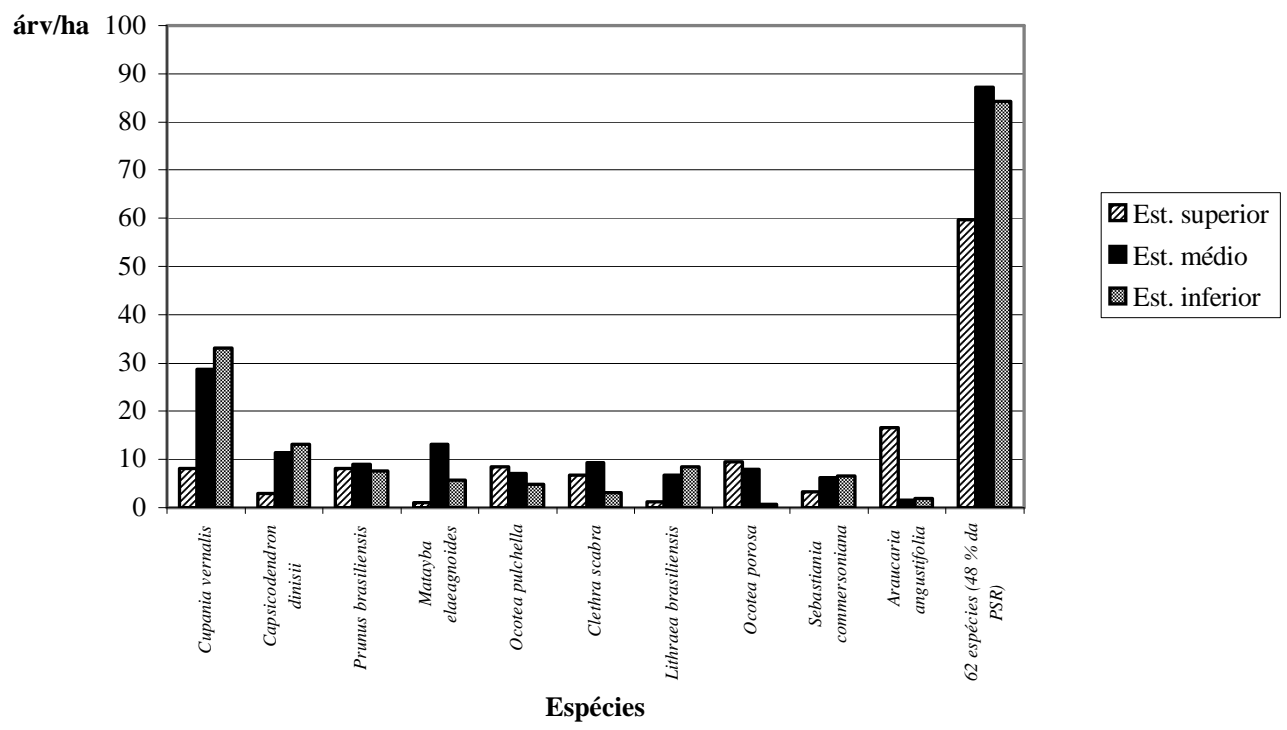

Figura 6. Distribuição do valor de importância (VI) das dez principais espécies amostradas na Reserva Florestal EMBRAPA/EPAGRI, Caçador, SC - Brasil.

Figure 6. Distribution of the importance value (IV) of the ten main species in the Forest Reserve EMBRAPA/EPAGRI, Caçador, SC - Brazil.

Depois de adicionar a PSR ao valor de importância (VI) (Figura 7), é possível observar algumas alterações na ordem de importância das espécies. Cupania vernalis, devido a seu alto valor de posição sociológica, superou a Araucaria angustifolia, para quem a inclusão da PSR não teve nenhuma significância, uma vez que obteve um valor baixo para esse parâmetro. A mesma situação aconteceu com Capsicodendron dinisii, que trocou de posição com Ocotea pulchella. Também Matayba elaeagnoides trocou de posição com Ocotea puberula. Cada uma dessas dez espécies obteve mais de 3\% de porcentagem de importância ampliada (PIA), acumulando em conjunto 53,5\% desse valor. No entanto, as outras 62 espécies, todas com menos de $3 \%$ de PIA, acumularam 46,5\%. As dez principais espécies da RFEE, segundo o valor de importância ampliado, foram Cupania vernalis, Araucaria angustifolia, Ocotea porosa, Capsicodendron dinisii, Prunus brasiliensis, Ocotea pulchella, Clethra scabra, Matayba elaeagnoides, Ocotea puberula e Sebastiania commersoniana.

$\mathrm{Na}$ figura 8 se observam as dez famílias com os maiores valores de importância (VI), representando 75,9\% do total, com as seguintes porcentagens de importância (PI): Lauraceae (15,9\%), Sapindaceae (13,6\%), Araucariaceae (11,5\%), Myrtaceae $(8,2 \%)$, Flacourtiaceae $(4,9 \%)$, Euphorbiaceae e Asteraceae $(4,8 \%)$, Rosaceae e Canellaceae $(4,2 \%)$ e Anacardiaceae $(3,9 \%)$. O alto valor para Lauraceae deve-se à elevada dominância, frequência e densidade das cinco espécies dessa família. $\mathrm{O}$ alto valor de Myrtaceae deveu-se à alta frequência e densidade. O mesmo se aplica à família Flacourtiaceae, que deve o seu valor principalmente às espécies Banara tomentosa e Casearia decandra. 


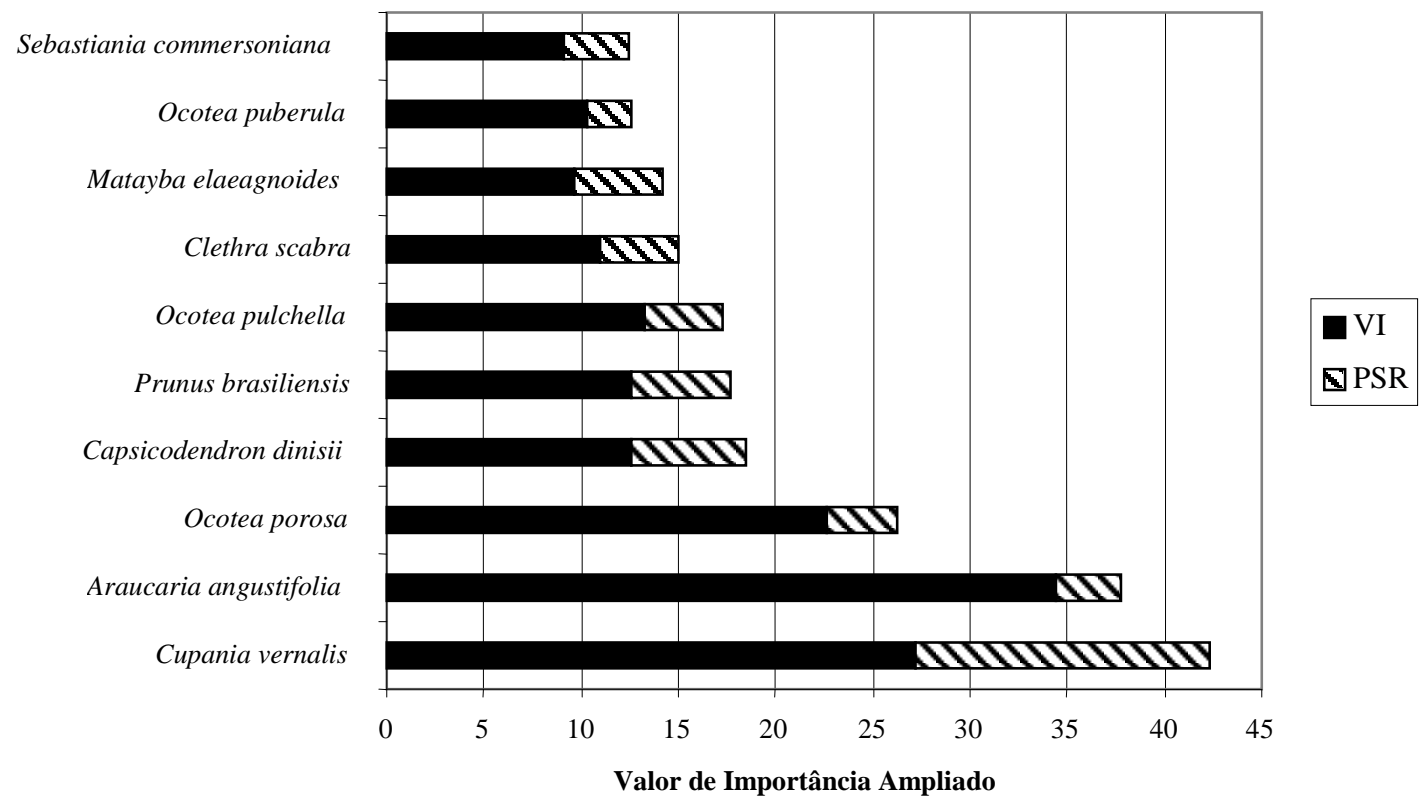

Figura 7. Distribuição do valor de importância ampliado (VIA) das dez principais espécies amostradas na Reserva Florestal EMBRAPA/EPAGRI, Caçador, SC - Brasil.

Figure 7. Distribution of the extended importance value (EIV) of the ten main species in the Forest Reserve EMBRAPA/EPAGRI, Caçador, SC - Brazil.

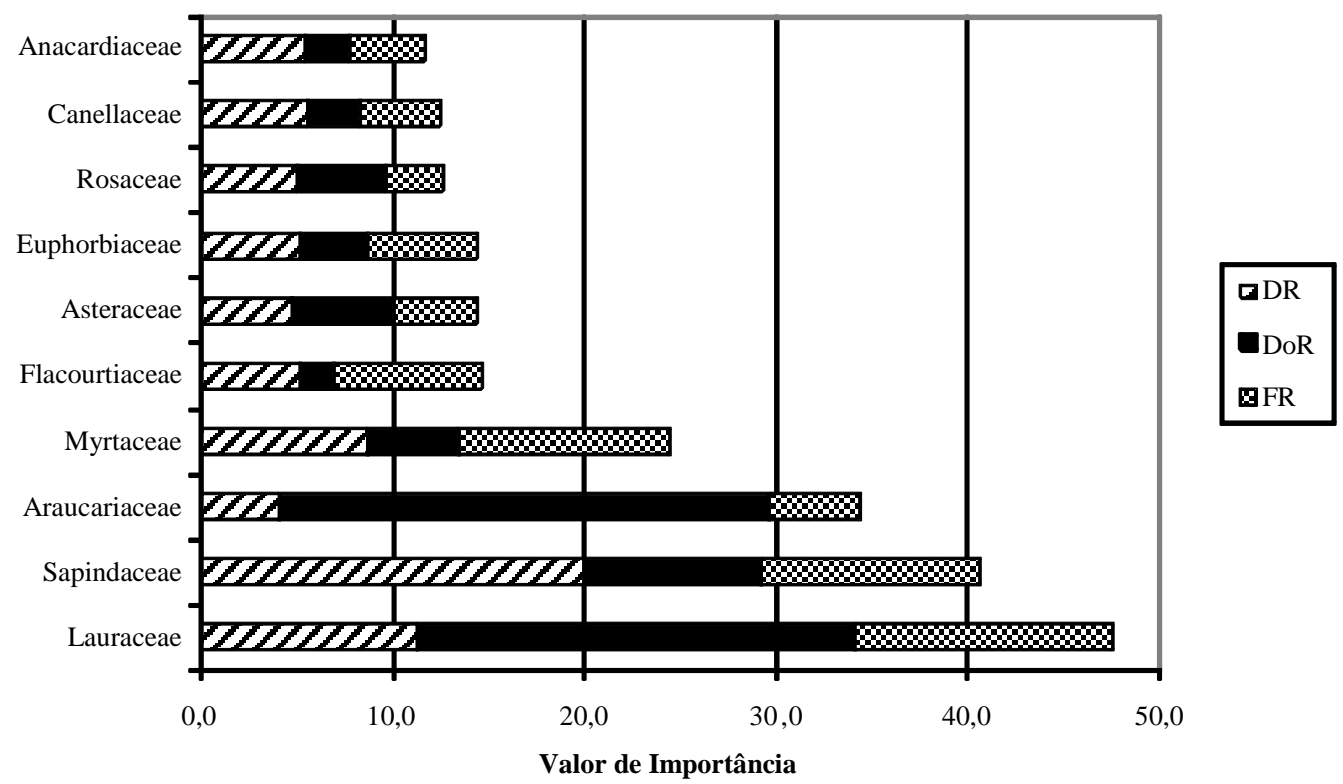

Figura 8. Distribuição do valor de importância (VI) das dez principais famílias amostradas na Reserva Florestal EMBRAPA/EPAGRI, Caçador, SC - Brasil.

Figure 8. Distribution of the importance value (IV) of the ten main species in the Forest Reserve EMBRAPA/EPAGRI, Caçador, SC - Brazil.

Nos trabalhos de Longhi (1980), Silva; Marconi (1990) e Rondon Neto et al. (2002a), desenvolvidos em uma área de FOM no Paraná, as principais oito, seis e cinco famílias, respectivamente, coincidiram com as principais famílias da presente pesquisa. Dos seis grupos florísticos definidos em uma 
área de FOM do Rio Grande do Sul por Longhi (1997), cinco a sete famílias desse estudo foram as mesmas que as determinadas neste trabalho. Na pesquisa de Nascimento et al. (2001) em Nova Prata (RS), seis famílias foram iguais às deste estudo. Embora essas pesquisas tenham sido realizadas em ambientes diferentes do da área deste trabalho, pode-se dizer que se confirma o padrão florístico que caracteriza a FOM nas áreas em que tal vegetação se desenvolve.

Para calcular a diversidade da comunidade florestal, empregou-se o índice de diversidade de Shannon (H'), que combina o número total de indivíduos e a densidade relativa das espécies, expressando a heterogeneidade florística de uma determinada área (PEET, 1974). O valor estimado H' para as espécies $\left(\mathrm{H}_{\text {esp }}\right)$ e famílias $\left(\mathrm{H}_{\text {fam }}^{\prime}\right)$ foi de 3,586 e 2,827 nats/ind., respectivamente. Esses valores são superiores aos encontrados em uma área de FOM do Paraná por Negrelle e Leuchtenberger $(2001)\left(\mathrm{H}_{\text {esp }}=3,538\right)$, Rondon Neto et al. (2002a) ( $\left.\mathrm{H}_{\text {esp }}=3,437 \mathrm{e} \mathrm{H}^{\prime}{ }_{\text {fam }}=2,693\right)$, Seger et al. (2005) ( $\left.\mathrm{H}_{\text {esp }}=2,37\right)$, Rivera (2006 - não publicado) $\left(\mathrm{H}_{\text {esp }}^{\prime}=3,454 \mathrm{e} \mathrm{H}^{\prime}{ }_{\text {fam }}=2,772\right)$, e inferiores aos valores encontrados em uma área de FOM do rio Passo Fundo (RS) por Longhi $(1997)\left(\mathrm{H}_{\text {esp }}=3,651\right)$.

Para o parâmetro forma do fuste, a grande maioria das espécies apresentou médias acima do valor 2 (67 espécies, que representam 93,1\% do total), ou seja, árvores com formas levemente tortuosas ou inclinadas. Mais da metade das espécies (39 espécies, que representam 54,2\%) apresentou valores médios acima 2,5, isto é, árvores com formas tortas ou danificadas, e apenas 5 espécies apresentaram médias abaixo do valor 2, representando $6,9 \%$ do total. Entre as últimas cinco, que apresentaram formas retas e cilíndricas, destacaram-se a Araucaria angustifolia, a Coutarea hexandra e a Symplocos tenuifolia, com médias abaixo do valor 1,5. À diferença do parâmetro forma, o parâmetro sanidade, para a maioria das espécies (63 espécies, que representam $87,5 \%$ do total), resultou em valores médios menores ou iguais a 1,5, o que significa que as árvores se encontram saudáveis. Inexistiram valores médios superiores a 2, indicando que praticamente toda a floresta não apresenta árvores na categoria "podre", embora existam alguns indivíduos com essa característica em 27 das 71 espécies.

Quando combinados os fatores de forma e sanidade, segundo a regra definida na Tabela 1, com o objetivo de gerar um valor de qualidade do fuste para as espécies assim como para as parcelas, observouse que apenas quatro espécies tiveram valores médios de qualidade do fuste que permitiu classificá-las como de "boa qualidade" (valor médio entre 1,0 e 1,64), sendo estas espécies as seguintes: Coutarea hexandra (1,0), Araucaria angustifolia (1,3), Symplocos tenuifolia (1,5) e Myrcia laruotteana var. paraguayensis $(1,6)$. Essas quatro espécies representaram 65 árvores $(5,3 \%)$ do total amostrado $(1.225)$, valor semelhante ao encontrado por Coraiola (1997) para a classe de melhor qualidade $(5,1 \%)$ numa floresta estacional semidecidual de Minas Gerais.

Por outro lado, 20 espécies tiveram valores médios de qualidade do fuste entre 1,65 e 2,34, classificando-se como de "qualidade média", o que corresponde a 214 indivíduos (17,5\% do total inventariado). No entanto, $66,7 \%$ (48 espécies) ficaram classificadas como de "má qualidade", devido a que suas médias ficaram com valores entre 2,35 e 3,00. Quando foi efetuada a análise de qualidade do fuste para as parcelas, encontraram-se os seguintes resultados: uma parcela (1,8\% do total) com qualidade boa (valor 1), 21 parcelas $(37,5 \%)$ com qualidade média (valor 2) e 34 parcelas $(60,7 \%)$ com qualidade má.

Esses resultados mostram que existe uma qualidade do fuste deficiente para a floresta como um todo, o que pode ser explicado por vários fatores. Um deles tem relação com o fato de que a RFEE segundo vários autores e também de acordo com os parâmetros obtidos nesta pesquisa - sofreu intervenções em que foram retirados os melhores indivíduos da floresta ("melhores" em termos madeireiros), deixando as espécimes com as piores características fenotípicas. Isso se confirma ao observar-se a má forma dos indivíduos dessa floresta e cuja descendência segue o mesmo padrão. Pelo contrário, a boa sanidade dessa floresta confirmaria que as florestas naturais recuperam-se bem das intervenções e conseguem rapidamente um equilíbrio interno.

\section{CONCLUSÕES}

- Pela composição florística (71 espécies, 33 famílias e 54 gêneros) determinada mediante o inventário florestal, constata-se que o padrão florístico que caracteriza a Floresta Ombrófila Mista também é seguido na RFEE. 
- A alta dominância relativa de Araucaria angustifolia e a alta densidade relativa de Cupania vernalis foram os fatores determinantes para que ambas as espécies obtivessem os dois mais altos valores de importância, permitindo dessa maneira que fossem classificadas como as duas principais espécies.

- Adicionar a posição sociológica relativa (variável de estrutura vertical) ao valor de importância (variável de estrutura horizontal) permitiu que espécies como Cupania vernalis, Capsicodendron dinisii e Matayba elaeagnoides tivessem aumento significativo na ordem de importância, ficando melhor situadas na posição ecológica que lhes corresponde na comunidade, o que permite utilizar o valor de importância ampliado como um índice para caracterizar melhor as florestas do ponto de vista estrutural.

- As alterações das estruturas horizontal e vertical da comunidade, assim como a má forma dos indíviduos presentes nela, apoiam o fato conhecido de que essa floresta sofreu intensa exploração seletiva de indivíduos de alto valor madeireiro de maior porte, como foi observado para Araucaria angustifolia (araucária) e Ocotea porosa (imbuia).

- A qualidade da floresta presente na RFEE, quando considerada a forma e a sanidade do fuste conjuntamente, pode ser classificada como deficiente, isto é, de média a má qualidade.

\section{REFERÊNCIAS}

CORAIOLA, M. Caracterização estrutural de uma Floresta Estacional Semidecidual localizada no município de Cássia - MG. 143 f. Dissertação (Mestrado em Ciências Florestais) - Setor de Ciências Agrárias, Universidade Federal do Paraná, Curitiba, 1997.

DA CROCE, D. Caracterização espacial estrutural e fitossociológica da Reserva Genética Florestal de Caçador - SC, através da análise de componentes principais e sistemas de informações geográficas. 120 f. Dissertação (Mestrado em Engenharia Agrícola) - Curso de Pós-Graduação em Engenharia Agrícola, Universidade Federal de Santa Maria - RS, Santa Maria, 1991.

DLUGOSZ, F.; ROSOT, N, ROSOT, A.; OLIVEIRA, Y. de. Uso da segmentação por crescimento de regiões em imagem Ikonos na discriminação de tipologias da Floresta Ombrófila Mista. In: SIMPÓSIO BRASILEIRO DE SENSORIAMENTO REMOTO (SBSR), 12, 2005, Goiânia. Anais. São José dos Campos: INPE, 2005. p. 1493-1500. CD-ROM.

EMBRAPA. Sistema Brasileiro de Classificação de Solos. 2.ed. Rio de Janeiro: Embrapa Solos, 2006. $306 \mathrm{p}$.

FINOL, H. Nuevos parámetros a considerarse en el análisis estructural de las selvas vírgenes tropicales. Revista Forestal Venezolana, Mérida, v. 14, n. 21, p. 29-42, 1971.

GALVÃO, F. Métodos de levantamento fitossociológico. Apostila da disciplina de Fitossociologia Florestal, Curso de Pós-graduação em Engenharia Florestal, UFPR. 2005. 18 p.

GALVÃO, F.; RODERJAN, C.; KUNIYOSHI, Y.; ZILLER, S. Composição Florística e Fitossociologia de caxetais do litoral do Estado do Paraná-Brasil. Floresta, Curitiba, v. 32, n. 1, p. 17-39, 2002.

GOMIDE, L.; SCOLFORO, J.; OLIVEIRA, A.; BORGES, L.; CAMOLESI, J.; GOMES, E.; SILVA, C.; CARVALHO, L. Estrutura horizontal de fragmentos florestais da bacia hidrográfica do rio São Francisco. In: MODELO fitogeográfico para áreas de preservação permanente: um estudo da bacia hidrográfica do rio São Francisco. Lavras: Editora UFLA, 2005. p. 137-198.

IBAMA - INSTITUTO BRASILEIRO DO MEIO AMBIENTE E DOS RECURSOS NATURAIS RENOVÁVEIS. Portaria № 37-N, de 03 de abril de 1992. Lista Oficial de Espécies da Flora Brasileira Ameaçadas de Extinção. 1992. 2 p.

IBGE - INSTITUTO BRASILEIRO DE GEOGRAFIA E ESTATÍstiCA. Manual Técnico da Vegetação Brasileira. Rio de Janeiro, 1991. 92 P. (Série de Manuais Técnicos em Geociências, n. 1). 
JARENKOW, J. Estudo fitossociológico comparativo entre duas áreas com mata de encosta no Rio Grande do Sul. 125 f. Tese (Doutorado em Ciências) - Universidade Federal de São Carlos, São Carlos, 1994.

KLEIN, R. O aspecto dinâmico do pinheiro brasileiro. A Araucaria angustifolia (Pinheiro), como espécie pioneira no atual ciclo climático. Sellowia, Itajaí, n. 12, p. 17-51, 1960.

KOZERA, C.; DITTRICH, V.; SILVA, S. Fitossociologia do componente arbóreo de um fragmento de Floresta Ombrófila Mista Montana, Curitiba, PR, BR. Floresta, Curitiba, v. 36, n. 2, p. 225-237, 2006.

KURASZ, G. Sistema de Informações Geográficas aplicado ao Zoneamento Ambiental da Reserva Florestal Embrapa/Epagri, Caçador-SC. 137 f. Dissertação (Mestrado em Ciências Florestais) - Setor de Ciências Agrárias, Universidade Federal do Paraná, Curitiba. 2005.

KURASZ, G.; FASOLO, P.; POTTER, R.; DLUGOSZ, F. GEBAUER, E.; ROSOT, M.; OLIVEIRA, Y de. Levantamento semidetalhado de solos para atualização de legenda na Reserva Florestal Embrapa/Epagri de Caçador-SC. In: EVENTO DE INICIAÇÃO CIENTÍFICA DA EMBRAPAFLORESTAS, 3., 2004, Colombo. Anais... Colombo, 2004. 12 p.

LAMPRECHT, H. Ensayo sobre la estructura florística de la parte sur-oriental del bosque universitario "El Caimital" - Estado Barinas. Revista Forestal Venezolana, Mérida, v. 7, n. 10-11, p. 77-119, 1964.

LEITE, P. As diferentes unidades fitoecológicas da região sul do Brasil: proposta de classificação. 160 f. Dissertação (Mestrado em Ciências Florestais) - Setor de Ciências Agrárias, Universidade Federal do Paraná, Curitiba. 1994.

LONGHI, S. A estrutura de uma floresta natural de Araucaria angustifolia (Bert.) O. Ktze, no sul do Brasil. 197 f. Dissertação (Mestrado em Ciências Florestais) - Setor de Ciências Agrárias, Universidade Federal do Paraná, Curitiba. 1980.

Agrupamento e análise fitossociológica de comunidades florestais na sub-bacia hidrográfica do rio Passo Fundo-RS. 198 f. Tese (Doutorado em Ciências Florestais) - Setor de Ciências Agrárias, Universidade Federal do Paraná, Curitiba. 1997.

MISSOURI BOTANICAL GARDEN. Trópicos. Disponível em: 〈http://www. mobot.org>. Acesso em: 20/08/2006.

NASCIMENTO, A.; LONGHI, S.; BRENA, D. Estrutura e padrões de distribuição espacial de espécies arbóreas em uma amostra de Floresta Ombrófila Mista em Nova Prata - RS. Ciência Florestal, Santa Maria, v. 11, n. 1, 105-119, 2001.

NEGRELLE, R.; LEUCHTENBERGER, R. Composição e estrutura do componente arbóreo de um remanescente de Floresta Ombrófila Mista. Floresta, Curitiba, v. 31. n. 1 e 2, p. 42-51, 2001.

NEGRELLE, R.; SILVA, F. Fitossociologia de um trecho de floresta com Araucaria angustifolia (Bert.) O. Ktze. No município de Caçador - SC. Boletim de Pesquisa Florestal, Curitiba, n. 24/25, p. 37-54, 1992.

MUELLER-DOMBOIS, D.; ELLENBERG, H. Aims and methods of vegetation ecology. New York: J. Wiley \& Sons, 1974. 547 p.

OLIVEIRA, Y. de; ROTTA, E. Levantamento da estrutura horizontal de uma mata de araucária no primeiro planalto paranaense. Boletim de Pesquisa Florestal, Curitiba, n. 4, p. 1-46, 1982.

PEET, R. The measurement of species diversity. Annual Review of Ecology and Systematics, Palo Alto, n. 5, p. 285-307, 1974

PUCHALSKI, A.; MANTOVANI, M.; REIS, M. dos. Variação em populações naturais de Araucaria angustifolia (Bert.) O. Kuntze associada a condições edafo-climáticas. Scientia Forestalis, Piracicaba, n. 70, p. 137-148, 2006. 
REIS, A. Manejo e conservação das florestas catarinenses. Trabalho para o concurso de professor titular da Universidade Federal de Santa Catarina - UFSC, Florianópolis, 1993. 124 p.

REITZ, R.; KLEIN, R.; REIS, A. Projeto madeira de Santa Catarina: Levantamento das espécies florestais nativas em Santa Catarina com a possibilidade de incremento e desenvolvimento. Iatjaí:SUDESUL, 1978. 320p. Convênio SUDESUL/Governo do Estado de Santa Catarina/IBDF.

RIVERA, H. Composição florística e análise fitossociológica de um fragmento de Floresta Ombrófila Mista da Floresta Estadual Metropolitana de Piraquara, PR - Brasil. Disciplina de Fitossociologia, UFPR. (não publicado). 2006. 15 f.

RIVERA, H.; RUDLOFF, A.; CRUZ, P. Plan de ordenación de la Reserva Nacional Valdivia. Una visión para el manejo ecológicamente sustentable de los ecosistemas forestales costeros de la $\mathbf{X}$ Región de Los Lagos: Proyecto Manejo Sustentable del Bosque Nativo (CONAF/GTZ). Santiago, Chile: CONAF/GTZ, 2002. 236 p.

RODAL, M.; SAMPAIO, E.; FIGUEIREDO, M. Manual sobre métodos de estudo florístico e fitossociológico. Ecossitema Caatinga. Bento Gonçalves, Sociedade Botânica do Brasil, 1992. 24 p.

RODERJAN, C.; GALVÃO, F.; KUNIYOSHI, Y.; HATSCHBACH, G. As unidades fitogeográficas do Estado do Paraná. Ciência e Ambiente, Santa Maria, n. 24. p. 75-92, 2002.

RONDON NETO, R.; KOZERA, C.; ANDRADE, R.; CECY, A.; HUMMES, A. FRITZSONS, E.; CALDEIRA, M.; MACIEL, M.; SOUZA, M. Caracterização florística e estrutural de um fragmento de Floresta Ombrófila Mista, em Curitiba, PR - Brasil. Floresta, Curitiba, v. 32, n. 1, p. 3-16, 2002a.

RONDON NETO, R.; WATZLAWICK, L. F.; CALDEIRA, M.; SCHOENINGER, E. Análise florística e estrutural de um fragmento de Floresta Ombrófila Mista Montana, situado em Criúva - RS, Brasil. Ciência Florestal, Santa Maria, v. 12, n. 1, p. 29-37, 2002 b.

SANQUETTA, C. R.; PIZATTO, W.; PÉLlICO NETTO, S.; FIGUEIREDO FILHO, A.; EISFELD, R. de L. Estrutura vertical de um fragmento de Floresta Ombrófila Mista no centro-sul do Paraná. Floresta, Curitiba, v. 32, n. 2, p. 267-276, 2002.

SEGER, C.; DLUGOSZ, F.; KURASZ, G.; MARTINEZ, D.; RONCONI, E.; MELO, L.; BITTENCOURT, S.; BRAND, M.; CARNIATTO, I.; GALVÃO, F.; RODERJAN, C. Levantamento florístico e análise fitossociológico de um remanescente de Floresta Ombrófila Mista localizado no Município de Pinhais, Paraná - Brasil. Floresta, Curitiba, v. 35, n. 2, p. 291-302, 2005.

SILVA, F.; MARCONI, L. Fitossociologia de uma floresta com araucária em Colombo-PR. Boletim de Pesquisa Florestal, Curitiba, n. 20, p. 23-38, 1990.

SILVA, A.; SCARIOT, A. Composição florística e estrutura da comunidade arbórea em uma floresta estacional decidual em afloramento calcário (Fazenda São José, São Domingos, GO, bacia do Rio Paraná). Acta Botânica Brasílica, São Carlos, 17, n. 2, p. 305-313, 2003.

SIMPLÍCIO, E. Determinação do tamanho de parcelas experimentais em povoamentos de Eucalyptus grandis Hill ex Maiden. 67 f. Dissertação (Mestrado) - Escola Superior de Agricultura de Lavras, Lavras, 1978.

WHITTAKER, R. Community and ecosystems. New York: MacMillan, 1975. 385 p. 